Full length article

\title{
A microfluidic oxygen sink to create a targeted cellular hypoxic microenvironment under ambient atmospheric conditions
}

\author{
Samineh Barmaki ${ }^{a}$, Ville Jokinen ${ }^{\mathrm{b}}$, Daniela Obermaier ${ }^{\mathrm{c}}$, Daria Blokhina ${ }^{\mathrm{a}}$, Matti Korhonen ${ }^{\mathrm{d}}$, \\ Robin H.A. Ras ${ }^{\mathrm{b}, \mathrm{e}}$, Jyrki Vuola ${ }^{\mathrm{f}}$, Sami Franssila ${ }^{\mathrm{b}}$, Esko Kankuri ${ }^{\mathrm{a}, *}$ \\ a Department of Pharmacology, Faculty of Medicine, University of Helsinki, Helsinki, Finland \\ ${ }^{\mathrm{b}}$ Aalto University, School of Chemical Engineering, Department of Chemistry and Materials Science, Espoo, Finland \\ c PreSens Precision Sensing GmbH, Regensburg, Germany \\ ${ }^{\mathrm{d}}$ Advanced Cell Therapy Centre, Finnish Red Cross Blood Service, Helsinki, Finland \\ e Aalto University, School of Science, Department of Applied Physics, Espoo, Finland \\ ${ }^{\mathrm{f}}$ Helsinki Burn Centre, Jorvi Hospital, Helsinki University Hospital and University of Helsinki, Helsinki, Finland
}

\section{A R T I C L E I N F O}

\section{Article history:}

Received 13 December 2017

Received in revised form 28 March 2018

Accepted 3 April 2018

Available online 9 April 2018

\section{Keywords:}

Hypoxia

Microenvironment

Cell culture

Microfluidic chip

Oxygen depletion

\begin{abstract}
A B S T R A C T
Physiological oxygen levels within the tissue microenvironment are usually lower than $14 \%$, in stem cell niches these levels can be as low as $0-1 \%$. In cell cultures, such low oxygen levels are usually mimicked by altering the global culture environment either by $\mathrm{O}_{2}$ removal (vacuum or oxygen absorption) or by $\mathrm{N}_{2}$ supplementation for $\mathrm{O}_{2}$ replacement. To generate a targeted cellular hypoxic microenvironment under ambient atmospheric conditions, we characterised the ability of the dissolved oxygen-depleting sodium sulfite to generate an in-liquid oxygen sink. We utilised a microfluidic design to place the cultured cells in the vertical oxygen gradient and to physically separate the cells from the liquid.

We demonstrate generation of a chemical in-liquid oxygen sink that modifies the surrounding $\mathrm{O}_{2}$ concentrations. $\mathrm{O}_{2}$ level control in the sink-generated hypoxia gradient is achievable by varying the thickness of the polydimethylsiloxane membrane.

We show that intracellular hypoxia and hypoxia response element-dependent signalling is instigated in cells exposed to the microfluidic in-liquid $\mathrm{O}_{2}$ sink-generated hypoxia gradient. Moreover, we show that microfluidic flow controls site-specific microenvironmental kinetics of the chemical $\mathrm{O}_{2}$ sink reaction, which enables generation of intermittent hypoxia/re-oxygenation cycles.

The microfluidic $\mathrm{O}_{2}$ sink chip targets hypoxia to the cell culture microenvironment exposed to the microfluidic channel architecture solely by depleting $\mathrm{O}_{2}$ while other sites in the same culture well remain unaffected. Thus, responses of both hypoxic and bystander cells can be characterised. Moreover, control of microfluidic flow enables generation of intermittent hypoxia or hypoxia/re-oxygenation cycles.
\end{abstract}

\section{Statement of Significance}

Specific manipulation of oxygen concentrations in cultured cells' microenvironment is important when mimicking low-oxygen tissue conditions and pathologies such as tissue infarction or cancer. We utilised a sodium sulfite-based in-liquid chemical reaction to consume dissolved oxygen. When this liquid was pumped into a microfluidic channel, lowered oxygen levels could be measured outside the channel through a polydimethylsiloxane PDMS membrane allowing only for gaseous exchange. We then utilised this setup to deplete oxygen from the microenvironment of cultured cells, and showed that cells responded to hypoxia on molecular level. Our setup can be used for specifically removing oxygen from the cell culture microenvironment for experimental purposes and for generating a low oxygen environment that better mimics the cells' original tissue environments.

(c) 2018 Published by Elsevier Ltd on behalf of Acta Materialia Inc.

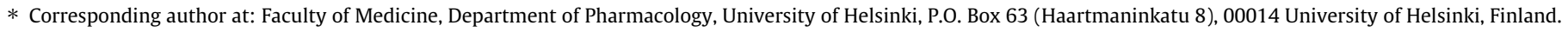
E-mail address: esko.kankuri@helsinki.fi (E. Kankuri).
} 


\section{Introduction}

Oxygen levels within human tissue microenvironments vary greatly with physiological oxygen levels or "physiological hypoxia", which is usually defined as $2-9 \%$ or $15-68 \mathrm{mmHg} \mathrm{pO}_{2}$ [1]. However, distinct anatomical locations and cell niches (such as the bone marrow) harbour even lower levels of $\mathrm{O}_{2}$ for functional maintenance, usually for stem cells or progenitors [2]. Under various pathological conditions, $\mathrm{pO}_{2}$ levels in the tissue microenvironment can undergo abrupt, intermittent or prolonged changes, such as is in vascular occlusion (infarction or ischemia) [3-5], and in many types of cancer [6,7]. For experimental tissue and cell culture purposes, mimicking a constantly lowered atmospheric $\mathrm{pO}_{2}$ is achievable by replacing ambient $\mathrm{O}_{2}$ with $\mathrm{N}_{2}$ in a closed culture atmosphere. This approach enables general assessment of cell responses to hypoxia under such an artificial environment against a control culture under normoxia. Generation of localised $\mathrm{pO}_{2}$ gradients using the $\mathrm{N}_{2} / \mathrm{O}_{2}$ gas replacement technique or oxygenscavenging chemicals (such as pyrogallol) have been utilised in microfluidic chips [8-10]. These techniques, however, are limited in their ability to combine selective $\mathrm{O}_{2}$ depletion and generation of spatially placed microenvironmental hypoxia in same culture conditions and vessel with unexposed cells. Furthermore, they cannot be flexibly modified for generation of hypoxia/re-oxygenation cycles or intermittent hypoxia under regular normal atmospheric cell culture conditions. Such difficult-to-achieve hypoxic cell culture conditions would take further hypoxia research and allow investigation of cell responses in a tissue-like setting where cellcell contacts, bystander cell effects and intercellular communication are appreciated.

Pyrogallol and sodium sulfite are the two preferred chemicals for oxygen depletion in microfluidic chips. Both react with molecular oxygen, thus depleting it from the vicinity of the occurring reaction. Here we focus specifically on the reaction of sodium sulfite with dissolved oxygen

$2 \mathrm{Na}_{2} \mathrm{SO}_{3}+\mathrm{O}_{2} \rightarrow 2 \mathrm{Na}_{2} \mathrm{SO}_{4}$

that requires cobalt nitrate $\mathrm{Co}\left(\mathrm{NO}_{3}\right)_{2}$ as catalyst and is $\mathrm{pH}$ dependent [11]. Shaikh and Zaidi [12] reported that the reaction rate is directly proportional to the concentration of the catalyst (cobalt sulphate in their experiments). They also reported that the reaction activation energy is $41.3 \mathrm{~kJ} / \mathrm{mol}$, and that the catalyst may significantly lower this activation energy. In concert with our results as well as the results by Fuller and Crist [11], Wilkinson et al. [13] reported that a decrease in $\mathrm{pH}$ also decreases the reaction rate. Linek and Tvrdik [14] reported a wide range for the rate constant of the reaction $\left(\mathrm{k}=1 \mathrm{~s}^{-1}-5 \times 10^{4} \mathrm{~s}^{-1}\right)$ that was dependent on catalyst concentration and $\mathrm{pH}$.

In this report, our aim was to generate hypoxia within the cellular microenvironment by meeting the aforementioned difficultto-achieve characteristics for a hypoxia cell culture platform to allow investigations under ambient atmospheric or routine cell culture conditions. We utilised the sodium sulfite chemical inliquid reaction to deplete dissolved oxygen and generate an $\mathrm{O}_{2}$ sink and out-of-liquid $\mathrm{O}_{2}$ gradient. Our aim was to place this chemical $\mathrm{O}_{2}$ sink in a contained microfluidic channel and evaluate its ability to modify cellular microenvironmental $\mathrm{O}_{2}$ levels through a gaspermeable polydimethylsiloxane (PDMS) membrane.

We present here a microfluidic conduit cell culture chip capable of controlled 2D microenvironmental oxygen removal utilising a flow-dependent, in-liquid chemical oxygen sink-generated oxygen gradient. The channel liquid oxygen sink is physically separated from the cells and their vertical placement in the oxygen gradient. Accordingly, the level of lowered oxygen tension is controlled by the thickness of the separating PDMS membrane. Furthermore, we demonstrate that the microenvironmental oxygen depletion is also translated into intracellular hypoxia response element (HRE)-dependent signalling. Our results enable controlled cellular level microenvironmental oxygen depletion and allow for microfluidic flow-dependent hypoxia-re-oxygenation cycles under normal atmospheric cell culture conditions.

\section{Materials and methods}

All reagents were obtained from Sigma Aldrich (St. Louis, MA) unless otherwise stated. A water solution of sodium sulfite (835 mM oxygen-depleted $\mathrm{H}_{2} \mathrm{O}$ ) was used to generate the oxygen sink. The reaction (1) of sodium sulfite $\left(\mathrm{Na}_{2} \mathrm{SO}_{3}\right)$ with dissolved oxygen in $\mathrm{H}_{2} \mathrm{O}$ was utilised for oxygen depletion and generation of an active in-liquid oxygen sink. Cobalt nitrate $\left(\mathrm{Co}\left(\mathrm{NO}_{3}\right)_{2}\right.$ hexahydrate salt, $9 \mathrm{mM}$ ) in nitric acid was used as the catalyst. To generate $\mathrm{O}_{2}$ saturated water, $100 \mathrm{ml}$ of water was bubbled for 15 min with $95 \%$ $\mathrm{O}_{2}$ and $5 \% \mathrm{CO}_{2}$.

HEK 293 cells (ATCC CRL-1573, Manassas, VA) were cultured in Dulbecco's Modified Eagle Medium (DMEM, Gibco, Thermo Fisher Scientific Inc, Waltham, MA) supplemented with $10 \%$ foetal bovine serum (FBS, Gibco) and antibiotics (penicillin, streptomycin). Cells from passages 16 to 33 were used for experiments. All cell culture experiments were performed under regular cell culture conditions in ambient oxygen levels at $37^{\circ} \mathrm{C}$ in a humidified atmosphere supplemented with $5 \% \mathrm{CO}_{2}$.

The VisiSens system (PreSens Precision Sensing GmbH, Regensburg, Germany) was used for imaging of oxygen levels. This system consists of a detection camera and $\mathrm{O}_{2}$-sensitive sensor membranes The sensor membrane consists of a polyester support and an $\mathrm{O}_{2^{-}}$ sensitive detection layer and is gas-permeable and flexible. VisiSens AnalytiCal 1 software (VA1.12, PreSens GmbH) was used for results analysis. For experiments on microfluidic chips, the sensor membranes were coated with PDMS and then integrated to the chip. Prior to use, the $\mathrm{O}_{2}$-sensitive sensor membranes were calibrated using either $\mathrm{O}_{2}$-depleted $\mathrm{H}_{2} \mathrm{O}-1\left(8 \mathrm{mM} \mathrm{Na}_{2} \mathrm{SO}_{3}\right)$ or $\mathrm{O}_{2}$ depleted $\mathrm{H}_{2} \mathrm{O}-2\left(835 \mathrm{mM} \mathrm{Na}_{2} \mathrm{SO}_{3}\right)$ as the 0-level standard [15], and $\mathrm{O}_{2}$-saturated $\mathrm{H}_{2} \mathrm{O}$ (prepared by bubbling water with $\mathrm{O}_{2}$ gas for $10 \mathrm{~min}$ ) as the 100 -level standard for the system. Oxygen measurements were then performed according to the manufacturer's instructions. For the droplet experiments, the size of the drops was $1-10 \mu \mathrm{l}$.

A galvanometric $\mathrm{O}_{2}$ sensor (WTW Oxygen portable meter ProfiLine Oxi 3310, Xylem Inc, Rye Brook, NY) was used to measure and verify dissolved oxygen concentrations $(\mathrm{mg} / \mathrm{l})$ in the solutions used.

\subsection{PDMS microfluidic chips}

PDMS is a widely used material for fabricating microfluidic chips. PDMS is biocompatible and can bind easily to glass or other PDMS layers by oxygen plasma treatment. Because PDMS is transparent at wavelengths $240-1100 \mathrm{~nm}$, this transparency facilitates the observation of contents in microchannels visually or through a microscope. PDMS was used as the material of choice for the microfluidic oxygen sink chip, as PDMS is highly permeable to oxygen [16].

PDMS (Sylgard 184) was used in this study at a 10:1 mixing ration of monomer:crosslinker. The reagents were mixed, degassed and cured in an oven at $70^{\circ} \mathrm{C}$ for $2 \mathrm{~h}$. PDMS films of $19,138,291$ and $580-\mu \mathrm{m}$ thickness were deposited by spin coating on top of oxygen sensors. The spin parameters were $2000 \mathrm{rpm}$ for $2 \mathrm{~min}$ to obtain $19-\mu \mathrm{m}$ thickness and $800 \mathrm{rpm}$ for $30 \mathrm{~s}$ to obtain $138-\mu \mathrm{m}$ thickness. The $291-\mu \mathrm{m}$ - and the $580-\mu \mathrm{m}$-thick films were made by utilising the 800 -rpm recipe two and four times, respectively, 
with a curing bake between the spinning steps. $1270-\mu \mathrm{m}$ - and $1620-\mu \mathrm{m}$-thick membranes were fabricated separately and bonded on top of the sensors with the same bonding process given below for bonding the microfluidic chips. The thicknesses of the membranes were measured by scanning electron microscopy.

The microfluidic chip design is shown in Fig. 1. The chip consists of a single inlet that simultaneously feeds two different designs for oxygen control areas. The channel width is $100 \mu \mathrm{m}$ and the depth is $37 \mu \mathrm{m}$. Oxygen sink area 1 is called the "pool" and is a wide but shallow (thickness $7.6 \mu \mathrm{m}$ ) channel that is supported by an array of micropillars (circular pillars, diameter $30 \mu \mathrm{m}$, spacing $100 \mu \mathrm{m}$, square lattice) as shown in Fig. 1B. The centre area of the pool is $5 \mathrm{~mm} \times 5 \mathrm{~mm}$; the $100-\mu \mathrm{m}$ feeding channel expands at a $45^{\circ}$ angle to this width. Oxygen sink area 2 is called the "meander" and is a meandering $100 \mu \mathrm{m}$ wide and $37 \mu \mathrm{m}$ thick channel that covers an area roughly $5 \mathrm{~mm} \times 5 \mathrm{~mm}$ (Fig. 1C). In between these two is a roughly $1 \mathrm{~cm} \times 1 \mathrm{~cm}$ central area that acts as the reference surface. The purpose of these two designs was to test two different approaches to create hypoxic conditions over a roughly $5 \mathrm{~mm} \times$ $5 \mathrm{~mm}$ area. The pillars in the pool area and the solid areas in the meander are needed to support the thin membrane so that it does not collapse and block the microfluidic channel.

The microchips are casted by replication moulding from SU-8 masters. The parameters used for the first layer $(7.6 \mu \mathrm{m})$ were the following: SU-8 5 spin-coated $1600 \mathrm{rpm}$ for $30 \mathrm{~s}$, soft bake on a hotplate for $5 \mathrm{~min}$ at $95^{\circ} \mathrm{C}$, UV exposure for $7 \mathrm{~s}$, post-exposure bake for $4 \mathrm{~min}$ at $95^{\circ} \mathrm{C}$. The parameters used for the second layer (total thickness $37 \mu \mathrm{m}$ ) were the following: SU-8 50 spin-coated $9000 \mathrm{rpm}$ for $30 \mathrm{~s}$, soft bake on a hotplate for $8 \mathrm{~min}$ at $95^{\circ} \mathrm{C}$, UV exposure for $12 \mathrm{~s}$, post exposure bake for $6 \mathrm{~min}$ at $95^{\circ} \mathrm{C}$. After development, the masters were coated with a Teflon-like PECVD fluoropolymer for anti-adhesion.

PDMS chips were casted using the SU- 8 masters to a thickness of 3.1-3.4 mm. After cutting and punching the chips, the chips were cleaned by pressing them against clean PDMS mixed at a 30:1 ratio, upon which all particles transferred to the 30:1 PDMS. The chips were then closed by bonding them with an oxygen per- meable $19-\mu$ m-thick PDMS membrane. The membrane was spincoated on top of a fluoropolymer-coated silicon wafer that acted as the carrier. Both the chip and the membrane were then exposed to oxygen plasma (PVA Tepla, $500 \mathrm{ml} / \mathrm{min}$ oxygen, $300 \mathrm{~W}$ power, 3-min treatment time). The chip and the membrane were then gently pressed together and the bonding was finished in oven at $70{ }^{\circ} \mathrm{C}$ for $15 \mathrm{~min}$. After bonding, the chips were peeled off the carrier silicon. Separate PDMS cell reservoirs were fabricated by manual cutting from 5- to 10 -mm-thick PDMS blocks. The cell culture reservoir was $7 \mathrm{~mm}$ high, $11 \mathrm{~mm}$ wide and $22 \mathrm{~mm}$ long with a total volume of $1.7 \mathrm{ml}$.

\subsection{Measurements of oxygen depletion in microfluidic chip}

After coating with a thin layer of PDMS, the oxygen sensor foil was attached to the microfluidic chip. Parts of the sensor foil remained uncovered by the chip and were used for drop calibration of the VisiSens camera. A $20 \mathrm{ml}$ syringe was connected to the chip by silicone tubing and a microfluidic syringe pump (NE-4000, New Era Pump Systems Inc, Farmingdale, NY) was used to control fluid flow in the microfluidic channel of the chip.

At the beginning of the $\mathrm{O}_{2}$-level imaging in the microfluidic chip, water was pumped for $2 \mathrm{~h}$ at a flowrate of $0.5 \mathrm{ml} / \mathrm{h} . \mathrm{O}_{2^{-}}$ depleted water was then pumped for $2 \mathrm{~h}$. Pumping was then stopped for $2 \mathrm{~h}$ to allow the chemical reaction to proceed in situ and to observe any oxygen build-up. Thereafter, pumping of $\mathrm{O}_{2-}$ depleted water commenced for $2 \mathrm{~h}$. Throughout the experiment, time-lapse images of the setup and sensor foil were collected at $20 \mathrm{~s}$ intervals using the VisiSens software.

\subsection{Preparation of microfluidic chips for cell culture}

The microfluidic chips were first washed thoroughly with soap and rinsed with deionized water. The chips were then dried and any remaining dust was removed with pressurised air. Before each experiment, the chips were rinsed with $70 \%$ ethanol and dried with pressurised air.

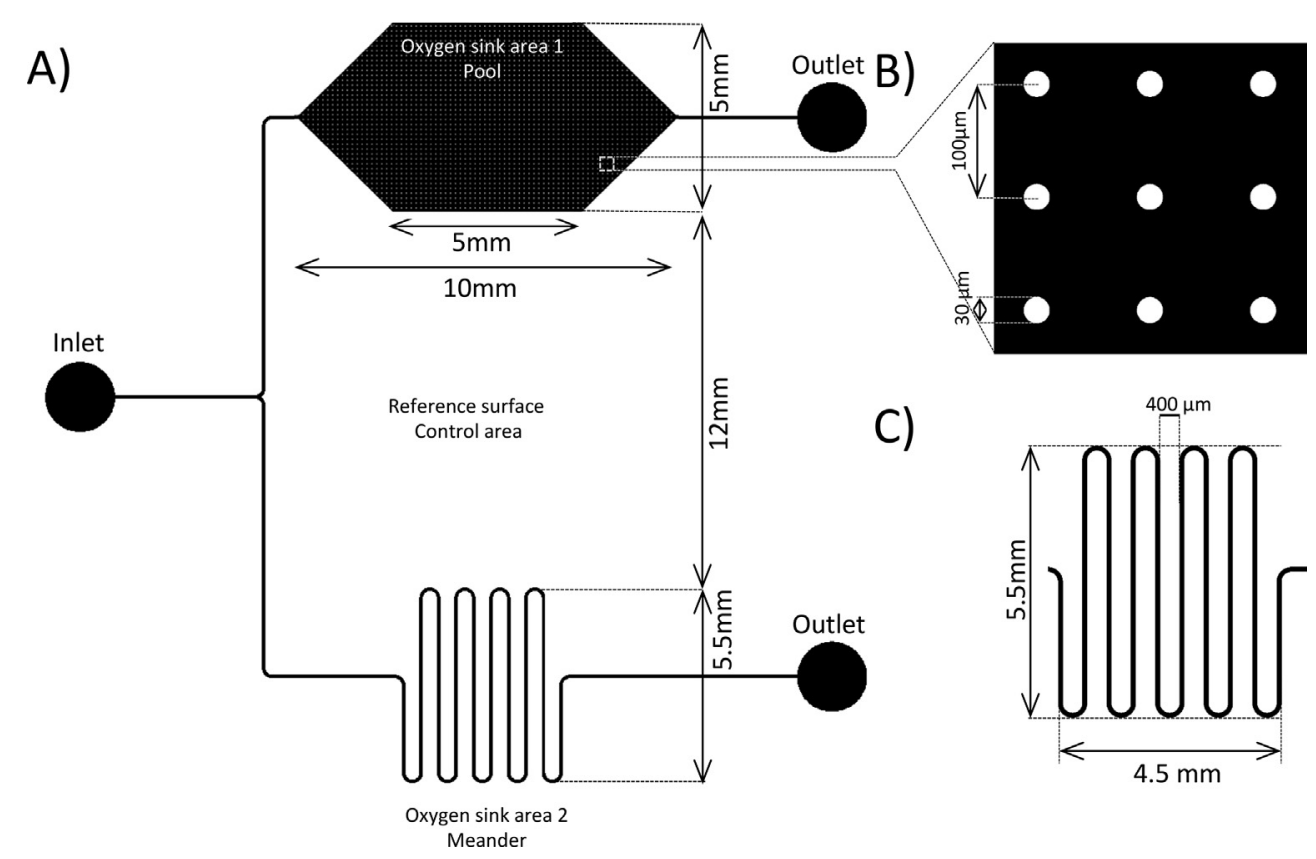

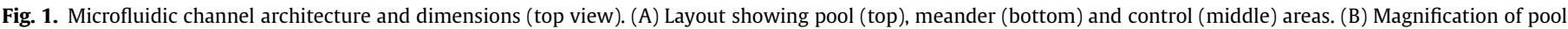
area showing pillar architecture (top view). (C) Meander area. 
Bovine fibronectin (F1141, Sigma Aldrich) at a final concentration of $10 \mu \mathrm{g} / \mathrm{ml}$ was used to coat the culture surfaces on microfluidic chips for $2 \mathrm{~h}$ before cell culture experiments. During coating, water was pumped through the channels to introduce a liquid phase (instead of a gaseous phase) beneath the culture area. After washing the chip cell culture reservoir with PBS at least three times, HEK 293 cells $\left(1 \times 10^{5}\right.$ cells/ml $)$ and culture medium were added to the reservoir. Cells were grown for $48 \mathrm{~h}$ on the microfluidic chips before initiating experiments.

\subsection{Fluorescence-activated cell sorting (FACS)}

FACS analyses were performed using the BD Accuri ${ }^{\mathrm{TM}}$ C6-flow cytometer (BD Biosciences Inc, San Jose, CA). HEK cells were first grown for $48 \mathrm{~h}$ on the fibronectin-coated microfluidic chip, then the spent medium was replaced by fresh medium and Image-iT ${ }^{\circledR}$ reagent was added. The microfluidic channel of the control chip remained filled with $\mathrm{H}_{2} \mathrm{O}$ and pumping of $\mathrm{O}_{2}$-depleted $\mathrm{H}_{2} \mathrm{O}$ was initiated into the microfluidic channel of the experiment chip with a flow-rate of $0.5 \mathrm{ml} / \mathrm{h}$. Both chips were incubated in the same culture incubator. After $13 \mathrm{~h}$, media (containing the non-adherent cells) from both culture reservoirs of the control and experiment chips were collected in separate conical $50 \mathrm{ml}$ tubes. $\mathrm{Ca}^{2+}$ and $\mathrm{Mg}^{2+}$-free PBS-containing $10 \mathrm{mM}$ ethylenediaminetetraacetic acid (EDTA, Gibco) was added to the reservoirs, incubated for $30 \mathrm{~min}$ to allow for adherent cell detachment and was collected as the adherent cell sample in FACS analysis.

In the forward scatter (FSC)-side scatter (SSC) plots, three populations of cells were gated and named P1, P2 and P3 for both control and experiment samples. To compare the Image-iT ${ }^{\circledR}$ fluorescence in control and experiment samples, SSC versus the fluorescence signal (FL3-A) was plotted. Histograms of cell counts in each gate and in the sum-gate against the FL3-A signal from the Image-iT ${ }^{\circledR}$ reagent for the cells from both control and experiment samples were plotted and analysed. An excitation wavelength of $488 \mathrm{~nm}$ and an emission wavelength filtering using a $610 / 20 \mathrm{~nm}$ filter was used to measure the fluorescence signal from Image-iT ${ }^{\circledR}$ reagent in cells.

\subsection{HIF response}

Image-i ${ }^{\circledR}$ Hypoxia reagent (Thermo Fisher Scientific, Waltham, MA) at a final concentration of $5 \mu \mathrm{M}$ was used to evaluate cellular oxygen levels. This reagent begins to fluoresce when atmospheric oxygen levels are less than 5\% [17]. After a 48-h incubation, the medium was replaced with $1 \mathrm{ml}$ of complete fresh culture medium containing $5 \mu \mathrm{M}$ Image-iT ${ }^{\circledR}$ Hypoxia reagent. Time-lapse imaging of the chip pool area was performed using a Nikon Eclipse Ti-E N-STORM microscope (Nikon Nikon Instruments Europe BV, Amsterdam, the Netherlands) at $100 \times$ magnification. The experiment duration was $19 \mathrm{~h}$ (oxygen-depleted water pumping speed $0.5 \mathrm{ml} / \mathrm{h}$ ) and images were recorded at $15 \mathrm{~min}$ intervals.

\subsection{Image analysis}

Image analysis was performed using Fiji ImageJ software version 2.0.0-rc-59/1.51k $[18,19]$.

\subsection{Statistical analysis and presentation of data}

Statistical analyses were carried out using GraphPad Prism 5.0 software (GraphPad Software Inc, La Jolla, CA). All data are presented as mean \pm standard deviation (SD).

\section{Results}

\subsection{Analysis of the sodium sulfite-induced oxygen depletion in droplets}

We evaluated the reaction of sodium sulfite with dissolved oxygen using an experimental droplet setup. This setup facilitates airliquid interaction by increasing the liquid-air interface area approximately 60-fold compared to measurement in a larger volume with a planar interface area (Fig. 2A). The droplet-sensor foil-camera setup allows for simultaneous detection of four droplets and thus inclusion of calibration standards with each measurement.

This method of fluorescent oxygen detection was validated in the droplet model by first preparing and measuring absolute dissolved oxygen concentrations of four solutions as follows: water bubbled with oxygen gas $\left(\mathrm{O}_{2}\right.$-saturated $\left.\mathrm{H}_{2} \mathrm{O}\right)$ contained $21 \mathrm{mg} / \mathrm{l}$ dissolved oxygen, deionized water $\left(\mathrm{H}_{2} \mathrm{O}\right)$ contained $7 \mathrm{mg} / \mathrm{l}$ dissolved oxygen, and two different chemical compositions of oxygen scavenger solutions: 1) $\mathrm{O}_{2}$-depleted $\mathrm{H}_{2} \mathrm{O}-1$ with $8 \mathrm{mM} \mathrm{Na}_{2} \mathrm{SO}_{3}$ and $859 \mu \mathrm{M} \mathrm{Co}\left((\mathrm{NO})_{3}\right)_{2}[15]$ and 2) $\mathrm{O}_{2}$-depleted $\mathrm{H}_{2} \mathrm{O}-2$ with $835 \mathrm{mM}$ $\mathrm{Na}_{2} \mathrm{SO}_{3}$ and $9 \mathrm{mM} \mathrm{Co}\left((\mathrm{NO})_{3}\right)_{2}$. Both oxygen scavenger solutions were measured to contain $0 \mathrm{mg} / \mathrm{l}$ dissolved oxygen using a membrane-covered galvanic dissolved oxygen sensor. The fluorescent sensor membrane was calibrated against $\mathrm{O}_{2}$-saturated $\mathrm{H}_{2} \mathrm{O}$ as 100 and $\mathrm{O}_{2}$-depleted $\mathrm{H}_{2} \mathrm{O}-1$ as 0 . Fig. 2B shows the percent fluorescently-measured oxygen saturation $\left(\% \mathrm{fs}_{2}\right)$ as measured over a $35 \mathrm{~min}$ time period for each liquid. The initial drop observed in the $\% \mathrm{fs}_{2}$ in oxygen-saturated water is most likely attributable to oxygen oversaturation that then stabilises over a short period of observation. The \% $\mathrm{fs}_{2}$ for $\mathrm{H}_{2} \mathrm{O}$ was $60.6 \pm 5.8$. The $\mathrm{O}_{2}$-depleted $\mathrm{H}_{2} \mathrm{O}-2$ demonstrated a sustained low level of $\% \mathrm{fsO}_{2}$ when compared with $\mathrm{O}_{2}$-depleted $\mathrm{H}_{2} \mathrm{O}-1$ with less sodium sulphite, which suggests reaction dependency on the availability of this reactant. The increase in the $\% \mathrm{fs}_{2}$ signal for $\mathrm{O}_{2}$-depleted $\mathrm{H}_{2} \mathrm{O}-1$ suggests that the dissolved oxygen concentration in the droplet increases over time putatively according to receding of the sodium sulfite reaction with dissolved oxygen, which leads to increased oxygen build-up in the droplet.

We further evaluated the role of sodium sulfite as the main reactant for oxygen depletion in $\mathrm{H}_{2} \mathrm{O}$. We measured the $\% \mathrm{fsO}_{2}$ changes in water containing cobalt nitrate and nitric acid with $(-0.1 \pm 7.0)$ or without $(72.4 \pm 6.1)$ sodium sulfite over time (Fig. 2C). Consistent with the galvanometrically measured dissolved oxygen concentrations, the $\% \mathrm{fsO}_{2}$ levels of the solution without sodium sulfite were comparable to those of water $\left(60.6 \pm 5.8 \% \mathrm{fsO}_{2}\right.$ and $6.9 \pm 0.8 \mathrm{mg} / \mathrm{l}$ dissolved $\left.\mathrm{O}_{2}\right)$. This demonstrates that neither cobalt nitrate as the reaction catalyst nor nitric acid interfere with $\% \mathrm{fsO}_{2}$ detection.

We then evaluated the ability of the $\% \mathrm{fs}_{2}$ droplet setup to detect the dependency of the sodium nitrate-oxygen reaction on cobalt nitrate (Fig. 2D) and pH (Fig. 2E), as previously reported [11]. Cobalt nitrate is utilised as a catalyst to facilitate the reaction between sodium sulfite and dissolved oxygen. The time-resolved \% $\mathrm{fsO}_{2}$ measurements showed a lower signal for the reaction solution with cobalt nitrate $\left(0.7 \pm 2.9 \% \mathrm{fsO}_{2}\right)$ when compared with the reaction solution without cobalt nitrate $\left(6.7 \pm 4.2 \% \mathrm{fsO}_{2}\right)$. This suggests that reaction catalysis with cobalt nitrate results in a more pronounced depletion of dissolved oxygen and facilitates the reaction, thus sustaining a lower dissolved level of oxygen over time (Fig. 2D). Based on the work by Fuller and Crist [11], by increasing the amounts of sodium sulfite, $\mathrm{pH}$ and oxygen absorption decreases over time. 
A)

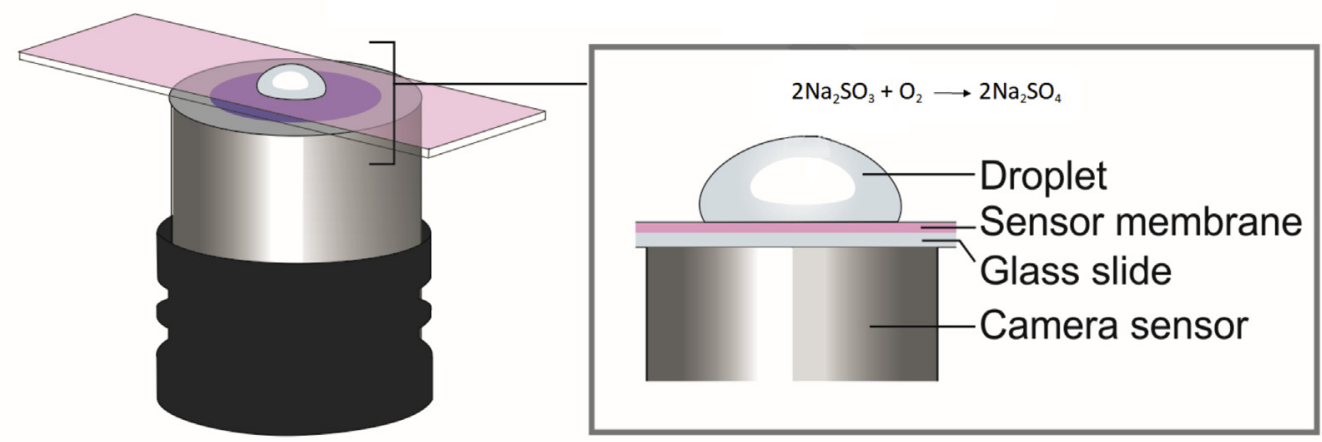

B)

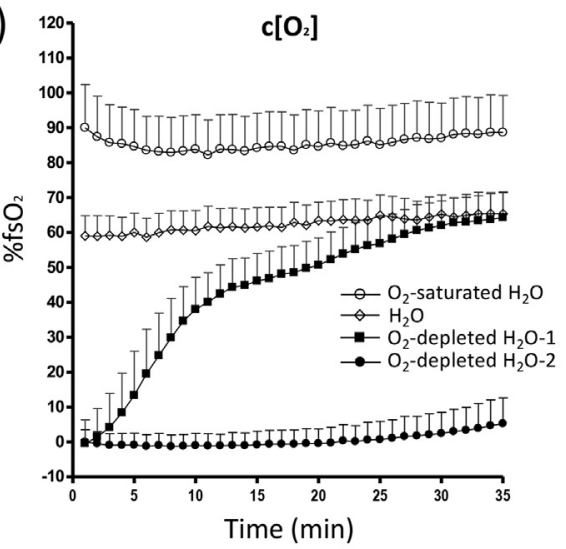

C)

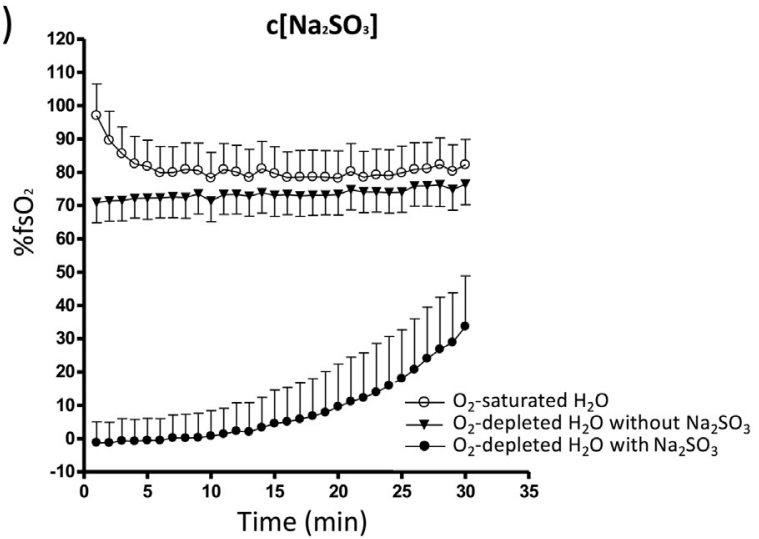

D)

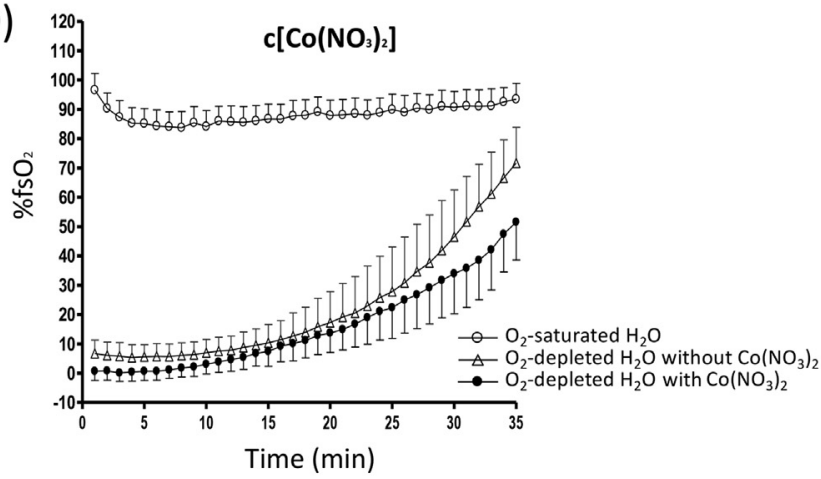

E)

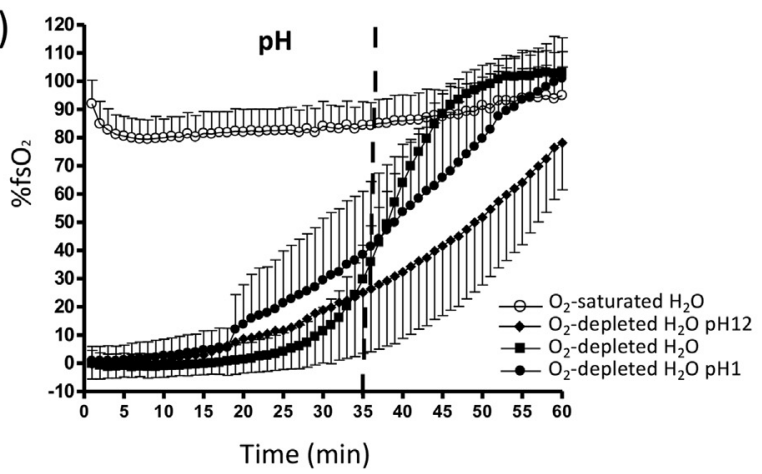

Fig. 2. \% $\mathrm{fs}_{2}$ in droplets. (A) Setup for the experiments with droplets. (B) \% $\mathrm{fs}_{2}$ in $\mathrm{O}_{2}$-saturated $\mathrm{H}_{2} \mathrm{O}$ and regular $\mathrm{H}_{2} \mathrm{O}$ against two types of sodium sulfite-containing and cobalt nitrate-containing $\mathrm{H}_{2} \mathrm{O}$. (C) Demonstration of substrate (sodium sulfite) dependency on $\mathrm{O}_{2}$ depletion and changes in dissolved $\mathrm{O}_{2}$ over time. (D) Effect of cobalt nitrate Co $\left(\mathrm{NO}_{3}\right)_{2}$ on \% $\mathrm{fs}_{2}$ as a measure of $\mathrm{O}_{2}$ buildup in the droplet. (E) $\mathrm{pH}$ dependency of initial dissolved oxygen depletion by sodium sulfite. $\mathrm{O}_{2}$ buildup in the droplet as an indicator for the sodium sulfite reaction with dissolved oxygen over time.

In our study, $\% \mathrm{fs}_{2}$ signals for oxygen-depleted water ( $\left.\mathrm{pH} 7\right)$, oxygen-depleted water with hydrochloric acid $(\mathrm{HCl})(\mathrm{pH} 1)$ and oxygen-depleted water with sodium hydroxide $(\mathrm{NaOH})(\mathrm{pH} 12)$ were determined by microscope on an oxygen sensor foil. Fig. $2 \mathrm{E}$ shows $\% \mathrm{fsO}_{2}$ changes in alkaline vs. acidic oxygen-depleted water. The $\% \mathrm{fsO}_{2}$ signal in alkaline oxygen depleted water was mostly stable from 0 to $35 \mathrm{~min}(0.4 \pm 4.4-33.5 \pm 12.2)$. Thereafter, in-droplet oxygen build-up starts to increase after $35 \mathrm{~min}-60 \mathrm{~min}$ $(36.0 \pm 12.8-103.2 \pm 7.2)$. The $\% \mathrm{fsO}_{2}$ signal changes in acidic $\mathrm{O}_{2}$-depleted water occurred slowly. Based on the results by Fuller and Crist [11], these $\% \mathrm{fsO}_{2}$ signal changes are due to slower reaction rate and thus slower consumption of the substrate.

\subsection{Effect of droplet displacement on PDMS on the fluorescently analysed oxygen signal}

Due to the effective removal of dissolved oxygen by sodium sulfite, we then utilised the droplet microscale model to evaluate the extent of this reaction outside the droplet. The reaction of sodium sulfite with dissolved oxygen that effectively proceeds within the droplet generates an oxygen void inside the droplet. Given that the droplet liquid is in interaction and equilibrium with the surrounding air (according to Henry's law), effective removal of dissolved oxygen by a chemical reaction inside the droplet generates an $\mathrm{O}_{2}$ gradient between these two phases. Moreover, 
oxygen from the surrounding air is thus constantly entering the droplet. Once the reaction kinetics slow down or sodium sulfite as the reactant is depleted, dissolved oxygen build-up occurs in the droplet. This dissolved oxygen can be measured as increased $\% \mathrm{fsO}_{2}$ over time. To demonstrate the formation of an oxygen gradient around the microscale droplet, we first utilised different thicknesses of the gas-permeable PDMS as both a physical separator and a displacement matrix for the droplet on the fluorescent sensor foil (Fig. $3 \mathrm{~A}$ ). The $\% \mathrm{fsO}_{2}$ readings of the $\mathrm{O}_{2}$-depleted $\mathrm{H}_{2} \mathrm{O}$ droplet were registered for the different thicknesses of PDMS directly cured on the sensor foil. In this setup, the sensor foil reacts to the oxygen concentrations in air at the sensor-PDMS interface level beneath the droplet. Because the PDMS coating can affect the sensor membrane's background signal, we corrected the droplet $\% \mathrm{fsO}_{2}$ measurements on PDMS coatings by simultaneously measuring a standardized non-coated sensor membrane with two calibration droplets. This allowed us to ascertain the same image analysis anchor for all PDMS thicknesses. Fig. 3B shows the backgroundcorrected $\% \mathrm{fsO}_{2}$ measurements in relation to PDMS thickness (h). Our results demonstrate that a gradient of lower oxygen concentration is generated in the surrounding air by the sodium sulfiteoxygen reaction within the droplet. We then calculated the equation for the gradient and the distance where the oxygen depletion effect remains at half the $\% \mathrm{fsO}_{2}$ level $\left(\mathrm{ED}_{50}\right)$, as measured with the droplet directly on the sensor membrane $(h=0)$. With the sodium sulfite concentrations used, we showed generation a droplet-surrounding oxygen gradient through PDMS with a distance of $1.5 \mu \mathrm{m}$ and a $50 \%$ fading distance $\left(\mathrm{FD}_{50}\right)$ of $664 \mu \mathrm{m}$. The PDMS thickness thus converts to $\% \mathrm{fs}_{2}$ following the equation:

$\% \mathrm{fsO}_{2} /$ background $=0.0006 * \mathrm{~h} / \mu \mathrm{m}+0.09$

\subsection{Evaluation of oxygen levels on PDMS above a microfluidic channel conduit}

To enable utilisation of the dissolved oxygen depletiongenerated oxygen gradient as a modifier of out-of-solution oxygen concentrations of a planar 2D surface, we generated a microfluidic chip consisting of the following three different study areas: larger area pool microfluidic channel, meander channel and a control area without a microfluidic channel. We then adhered the fluorescent oxygen sensor membrane to $30-\mu \mathrm{m}$-thick PDMS that was placed on the microfluidic channel to seal the channel. We used a constant flow rate of $0.5 \mathrm{ml} / \mathrm{h}$ to determine oxygen concentrations and oxygen signal stability in the chip channel. First, normal water $\left(\mathrm{H}_{2} \mathrm{O}\right)$ was pumped into the channel followed by pumping of $\mathrm{O}_{2}$ depleted water. Pumping was then stopped to evaluate oxygen build-up within the channel and to evaluate the permeability of the setup to outside oxygen. Fig. $4 \mathrm{~A}$ shows the $\% \mathrm{fsO}_{2}$ measurements from the chip pool area; Fig. $4 \mathrm{~B}$ shows the $\% \mathrm{fsO}_{2}$ measurements from the meander area. Control area $\% \mathrm{fs}_{2}$ remained at background level. At $\mathrm{H}_{2} \mathrm{O}$ pumping (Fig. $4 \mathrm{~A}-\mathrm{I}$ ), the initial $\% \mathrm{fs}_{2}$ at

A)

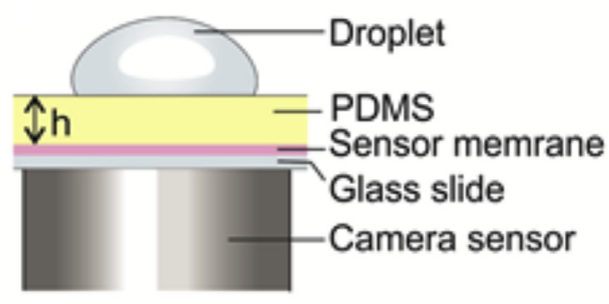

B)

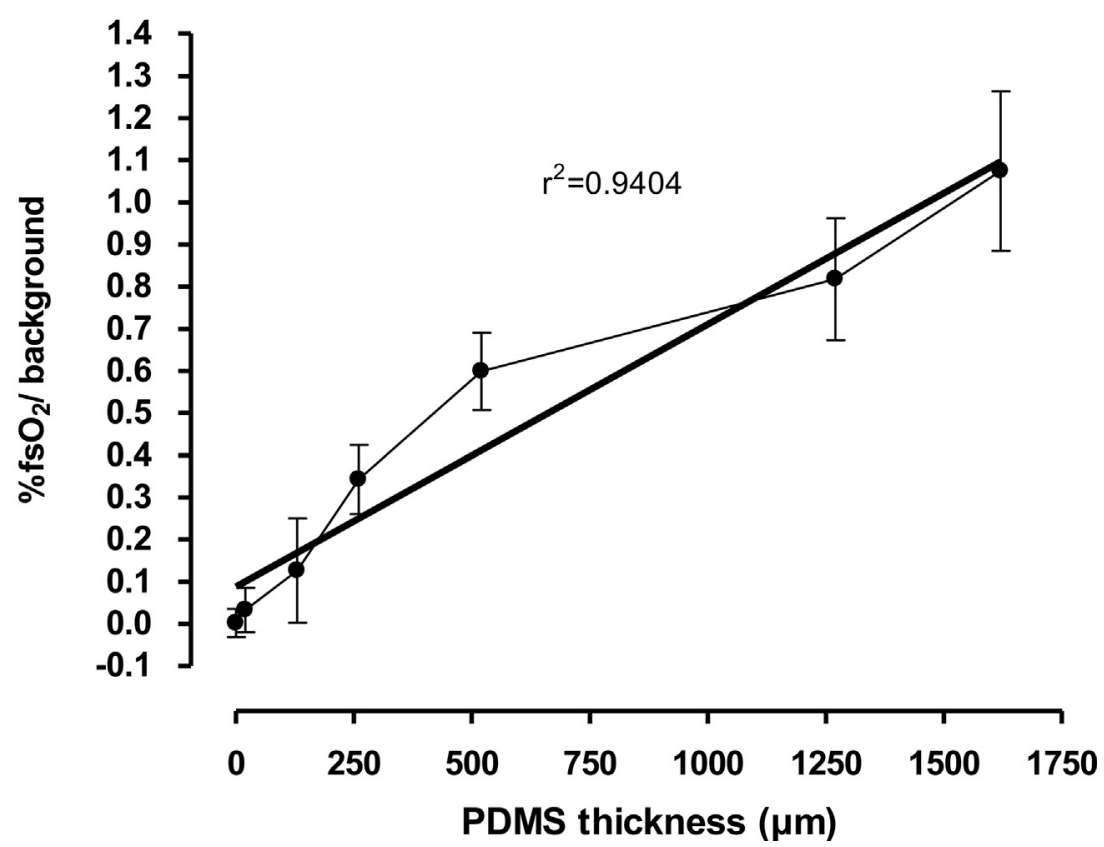

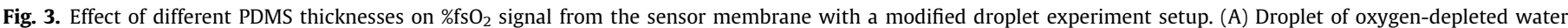

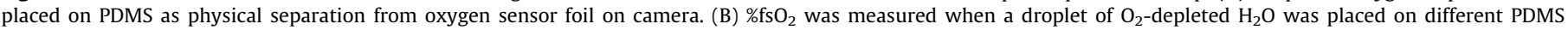
thicknesses $(\mu \mathrm{m})$. Linear correlation (line) with the correlation coefficient $\left(\mathrm{r}^{2}\right)$ is shown. 

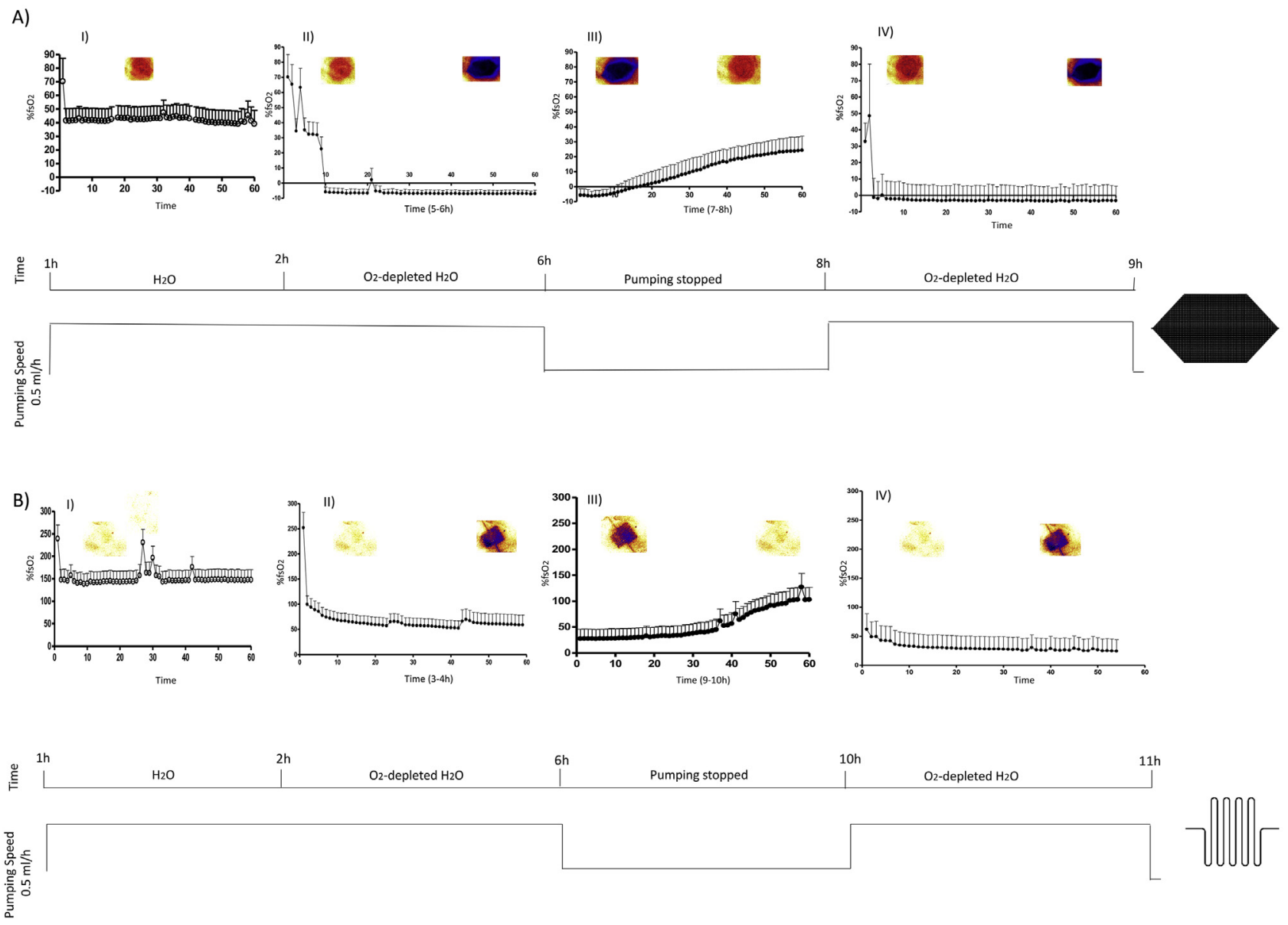

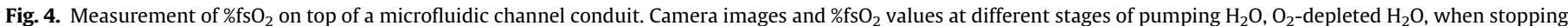
pumping and re-pumping of $\mathrm{O}_{2}$-depleted $\mathrm{H}_{2} \mathrm{O}$ at $5 \mathrm{ml} / \mathrm{h}$ on (A) the pool area and (B) the meander area.

the pool area was $52.0 \pm 8.2$ but rose to $53.7 \pm 9.7$ at the end Thereafter, we introduced $\mathrm{O}_{2}$-depleted water into the channel and measured a rapid drop in $\% \mathrm{fsO}_{2}$ to even below 0-calibration levels within 10 min after the $\mathrm{O}_{2}$-depleted water reached the pool area (1h $10 \mathrm{~min}$ ). This suggests a highly efficient or even complete removal of oxygen at the sensor membrane level on top of the PDMS covering the microfluidic channel. This effectively reduced $\% \mathrm{fsO}_{2}$ level remained stable throughout the pumping period (Fig. $4 \mathrm{~A}-\mathrm{II}$ ). When pumping was stopped (Fig. $4 \mathrm{~A}-\mathrm{III}$ ), the $\% \mathrm{fsO}_{2}$ signal from the channel pool area began to increase at $1 \mathrm{~h} 10 \mathrm{~min}$ and reached $34.5 \pm 11.5$ at $2 \mathrm{~h}$, suggesting exchange of oxygen in the channel liquid with the outside air through the PDMS. After pumping and fluid flow were again initiated, the $\% \mathrm{fsO}_{2}$ levels in the pool area rapidly (within 2 min) dropped back to sub-zero levels $(-3.2 \pm 8.8)$.

We then repeated this same sequence of pumping and $\% \mathrm{fs}_{2}$ measurements in the meander area of the microfluidic channel (Fig. 4B). When $\mathrm{H}_{2} \mathrm{O}$ was pumped to the channel (Fig. 4B-I), a higher $\% \mathrm{fsO}_{2}$ signal of $204.9 \pm 25.7$ than that from the pool area was observed, suggesting a more effective dynamic exchange of oxygen with the surrounding air through the PDMS. Pumping of $\mathrm{O}_{2}$-depleted $\mathrm{H}_{2} \mathrm{O}$ into the channel reduced the overall \% $\mathrm{fsO}_{2}$ signal from the meander area to $58.8 \pm 19.7$ (Fig. 4B-II). When pumping was stopped, an increase in $\% \mathrm{fsO}_{2}$ signal was observed at $3 \mathrm{hr}$ and $40 \mathrm{~min}$, rising gradually to $102.7 \pm 23.8$ level. This increase in \% $\mathrm{fsO}_{2}$ occurred faster in the pool area than in the meander area (1h $10 \mathrm{~min}$ vs. $3 \mathrm{~h} 40 \mathrm{~min}$ ) and showed an increased range (30.8 $\pm 19.3-102.7 \pm 23.8$ ) (Fig. 4B-III). When pumping of $\mathrm{O}_{2}$-depleted $\mathrm{H}_{2} \mathrm{O}$ was reinstated, the $\% \mathrm{fsO}_{2}$ signal in the meander area was reduced to low levels $(24.3 \pm 19.8)$ within 20 min. Therefore, by comparing pool vs meander area, the pool area's larger area of interaction with the oxygen-depleted $\mathrm{H}_{2} \mathrm{O}$ facilitates more efficient $\mathrm{O}_{2}$ depletion. Also, due to the larger size and fraction of the solid areas of the meander compared to the micropillar supports of the pool, the oxygen-depleted area on top of the meander was less uniform. Some of the channel shape is visible on Fig. 4B, instead of the whole area equally oxygen depleted. Finally, due to the shallower nature of the pool area, there is less stored liquid at any time under the critical area. Therefore, the pool area reacts faster to stopping the pumping, allowing for faster changes in the oxygen concentration.

Taken together, our results confirmed the formation of a 2D uniform oxygen level at the site physically separated from the microfluidic channel. The low $\% \mathrm{fsO}_{2}$ values were restricted to the sites above the microfluidic channel, whereas in areas outside the channels the \% $\mathrm{fsO}_{2}$ levels remained at background level. However, at sites directly adjacent to the channel, a $\% \mathrm{fsO}_{2}$ signal gradient was observed. This suggests formation of a 2D oxygen gradient outwards from the channel in the plane of the sensor membrane at a $30 \mu \mathrm{m}$ distance from the microfluidic channel that contains $\mathrm{O}_{2^{-}}$ depleted $\mathrm{H}_{2} \mathrm{O}$. The results confirm formation of a hypoxic to anoxic microenvironment driven solely by removal of oxygen as induced 
by the formation of a chemically-driven oxygen sink within the $\mathrm{O}_{2}$-depleted $\mathrm{H}_{2} \mathrm{O}$. Supplementary Video 1 presents the $\% \mathrm{fsO}_{2}$ in pool channel of the microfluidic chip on oxygen sensor foil.

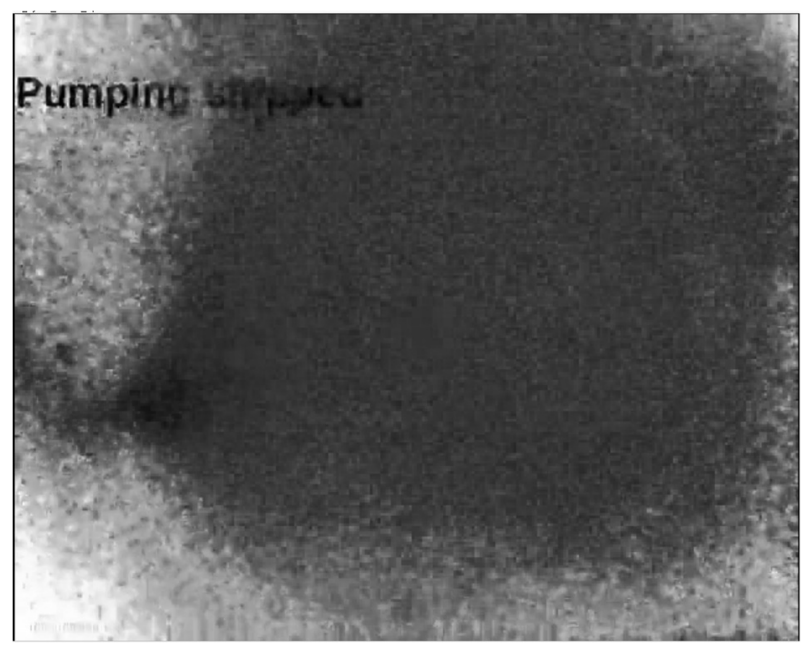

Supplementary Video 1 . The video shows $\% \mathrm{fs}_{2}$ measured with the $\mathrm{O}_{2}$ sensor membrane using the VisiSens system from the pool area of the microfluidic chip. $\mathrm{H}_{2} \mathrm{O}$ was first pumped for $1 \mathrm{~h}, \mathrm{O}_{2}$-depleted $\mathrm{H}_{2} \mathrm{O}$ pumped for $4 \mathrm{~h}$, then pumping stopped for $2 \mathrm{~h}$ and finally $\mathrm{O}_{2}$-depleted $\mathrm{H}_{2} \mathrm{O}$ repumped for $1 \mathrm{~h}$.

\subsection{Cells-on-chip}

In order to physically seal the microfluidic channel and to allow gas permeability (thus enabling utilisation of the oxygen gradient generated by the chemical oxygen sink in the channel), we covered the channel with a 30- $\mu \mathrm{m}$-thick PDMS membrane. A silicon reservoir for cells and culture medium was then integrated on top of the PDMS membrane (Fig. 5A). Because PDMS as such is not an optimal substrate for adherent cell binding, we coated the PDMS membrane with fibronectin before initiating cell cultures. HEK cells adhered and grew well on top of the collagen-coated PDMS membrane; switching fluid pumping on or off in the channel beneath the cultures had minimal mechanical effect on cell growth and adherence.

The right panel in Fig. 5A shows the full cell culture setup. We used a single common reservoir encompassing all culture areas, including the meander and pool microfluidic channel architectures and the control area (no channels underneath the cultured cells). The single reservoir setup was chosen to further demonstrate the 2D resolution of our chip construct to selectively modify only those areas that are directly adjacent to the chemical oxygen sinkgenerated hypoxic gradient. Moreover, our aim was to demonstrate that the gradient does not affect the bystander, adjacent cells of the control area that are in immediate vicinity and in the same culture medium environment.

Prior to pumping of the oxygen-depleted $\mathrm{H}_{2} \mathrm{O}$ into the channel, the HEK cells were loaded with Image-iT ${ }^{\circledR}$ hypoxia reagent, which is a hypoxia indicator fluorescent dye. This reagent has been shown to reversibly respond with fluorescence intensity directly proportional to alterations in oxygen levels and to HIF- $1 \alpha$ expression [17]. Fig. 5B shows fluorescence intensity of cells and the representative images of the pool area over $12 \mathrm{~h}$ of pumping oxygendepleted $\mathrm{H}_{2} \mathrm{O}$ through the microfluidic channel. Cells on top of both the pool and meander area showed clear red fluorescence. Cells in the area without exposure to the microfluidic channel remained non-fluorescent, which suggests a site-specific, microfluidic channel architecture-selective microenvironmental targeting of the chemical oxygen sink-generated oxygen depletion. All cell culture experiments were conducted in a cell culture incubator under a controlled humidified normoxic environment at $+37{ }^{\circ} \mathrm{C}$ supplemented with $5 \% \mathrm{CO}_{2}$. Throughout the experiment the $\mathrm{pH}$ of the culture medium was closely monitored for any changes by the $\mathrm{pH}$ indicator phenol red. No changes in the $\mathrm{pH}$ of the culture medium were observed during the experiments. The $\mathrm{pH}$ of the sodium sulfite-containing oxygen-depleted water was 7. Supplementary Video 2 presents a time-lapse recording of the fluorescent signal in the cells on the microfluidic chip pool area.

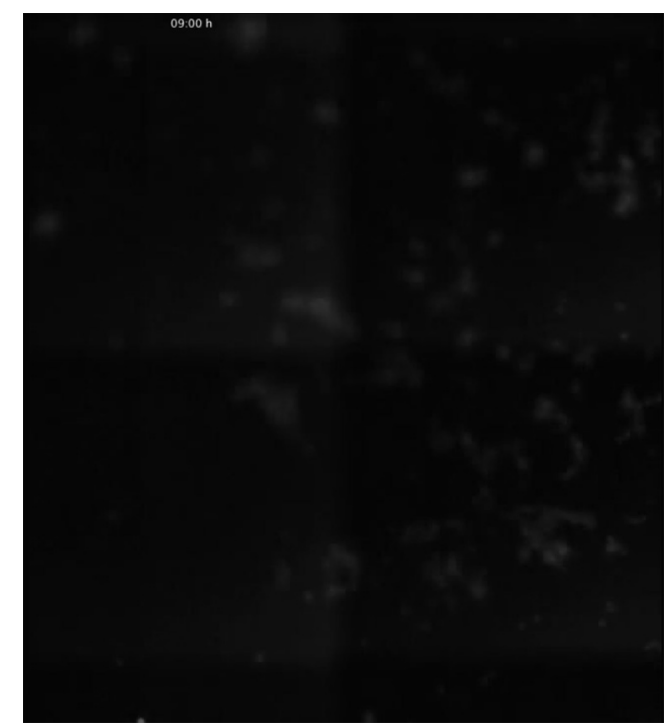

Supplementary Video 2. Time-lapse fluorescence image series captured using the Nikon Eclipse Ti-E N-STORM microscope showing intensity of Image-iT ${ }^{\circledR}$ reagent signal in HEK cells on the microfluidic chip pool area at 2-12 h of pumping of $\mathrm{O}_{2}$ depleted $\mathrm{H}_{2} \mathrm{O}$. Signal intensity began to increase after $6 \mathrm{~h}$ of pumping reaching a maximum plateau level at 9-10 $\mathrm{h}$.

After $14 \mathrm{~h}$ of pumping oxygen-depleted $\mathrm{H}_{2} \mathrm{O}$ (experiment) or $\mathrm{H}_{2} \mathrm{O}$ (control), both non-adherent and adherent cell populations were collected from the microfluidic culture chip. Cell analysis was performed using FACS. Fig. $6 \mathrm{~A}$ and $\mathrm{C}$ shows the FACS analysis results of non-adherent cells at the end of the experiment. The left panels of Fig. 6A show the cells as function of their size (FSC-A) against their intracellular granularity or complexity (SSC-A). Three populations were discernible according to size and granularity (P1-3). Significantly more cells (5.3-fold more; 9945 vs. 1868) were detached from the culture chip under experiment conditions. In these conditions, cells in the pool and meander area were exposed to the microenvironmental hypoxia instigated by the chemical oxygen sink-generated oxygen gradient as compared with the control conditions (microfluidic channels filled with $\mathrm{H}_{2} \mathrm{O}$ ). Right panels of Fig. 6A show overlays of the three populations in terms of intracellular fluorescence (FL3-A) and granularity. As shown in the lower right quadrant of the FACS histogram, under experiment conditions 13-fold (25.9\%) more cells showed significantly increased fluorescence when compared with control conditions (2.0\%). Further analysis of fluorescence intensity in the populations (P1-3) is shown in Fig. 6C. The increase in fluorescence is evident in all populations. In the experiment condition, two new cell populations emerge in P1 and P2, showing small (P1) and large cell (P2) sizes. This suggests that both live and dying cells detached from the chip culture surface were exposed to lowered oxygen levels. The fluorescence from the larger cells also produced a clear double peak that is visible in the detailed P2 cell population gate (Fig. 6C).

Similar to the analysis detailed above for the non-adherent cell, Fig. $6 \mathrm{~B}$ and $\mathrm{D}$ show the cells remaining adherent at the end of the 
A)

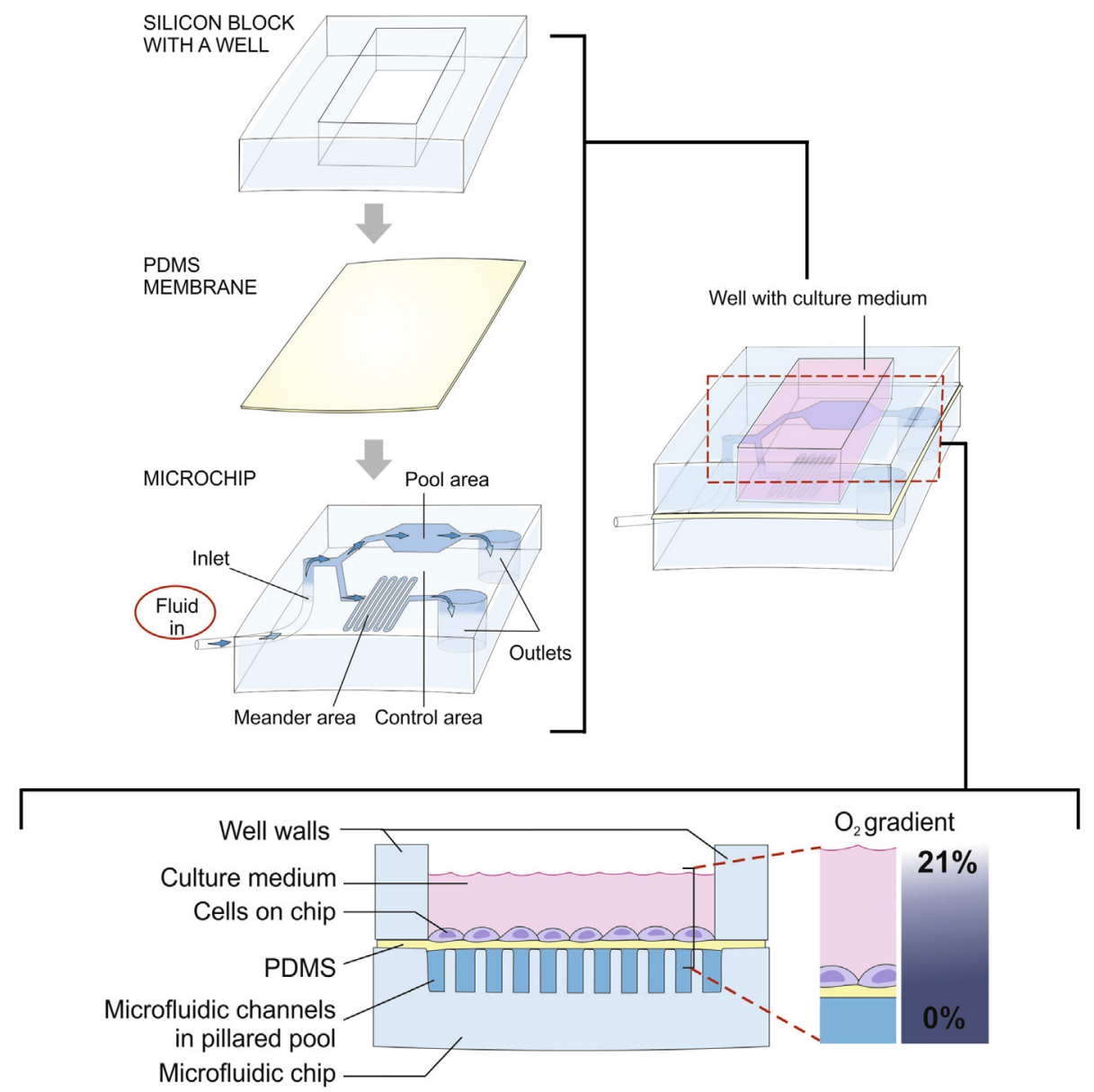

B)

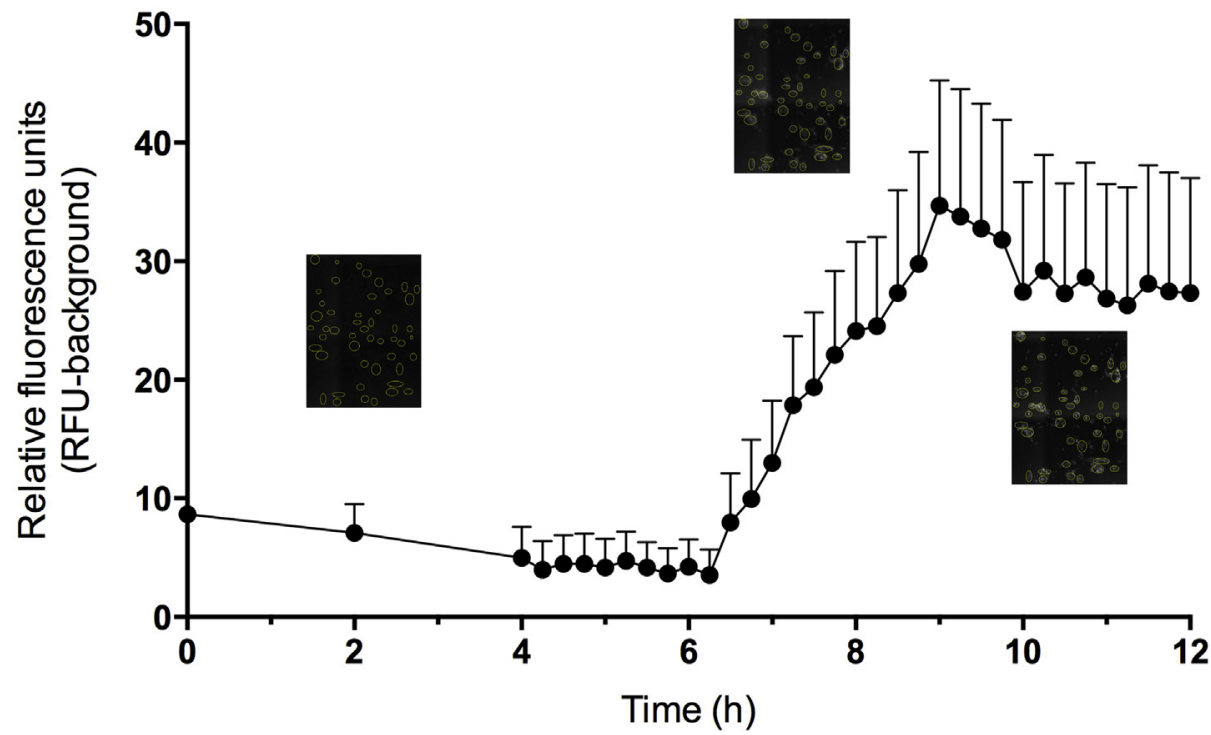

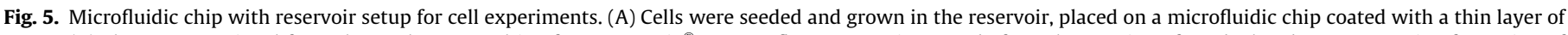

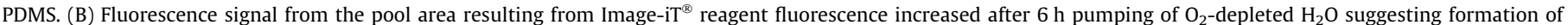
intracellular hypoxia. 
Non-adherent cells
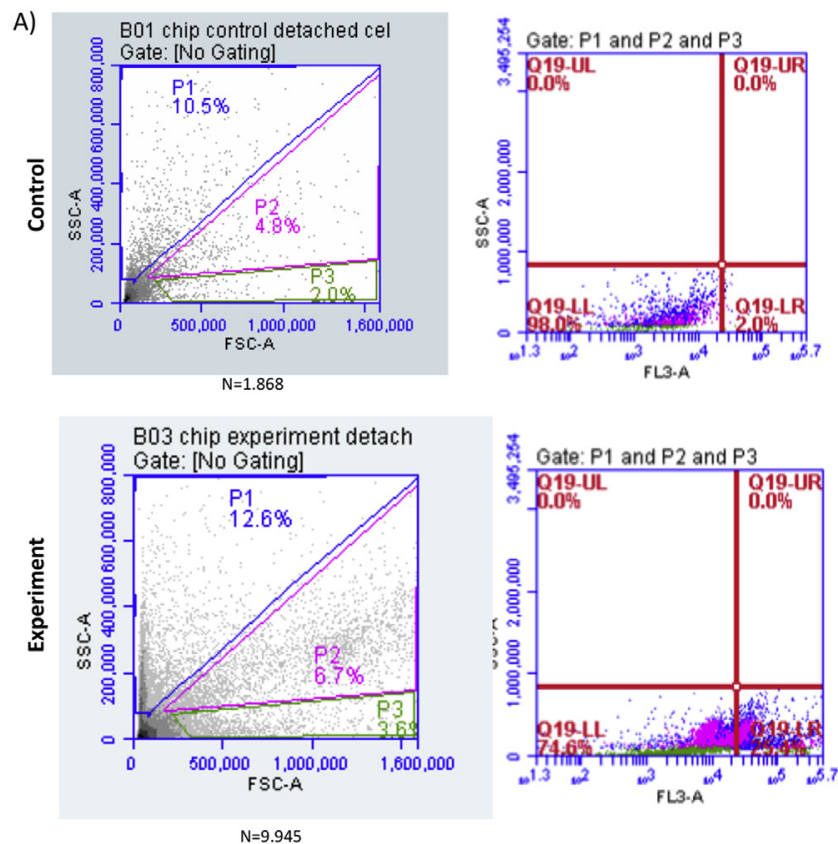

C)

Non-adherent cells
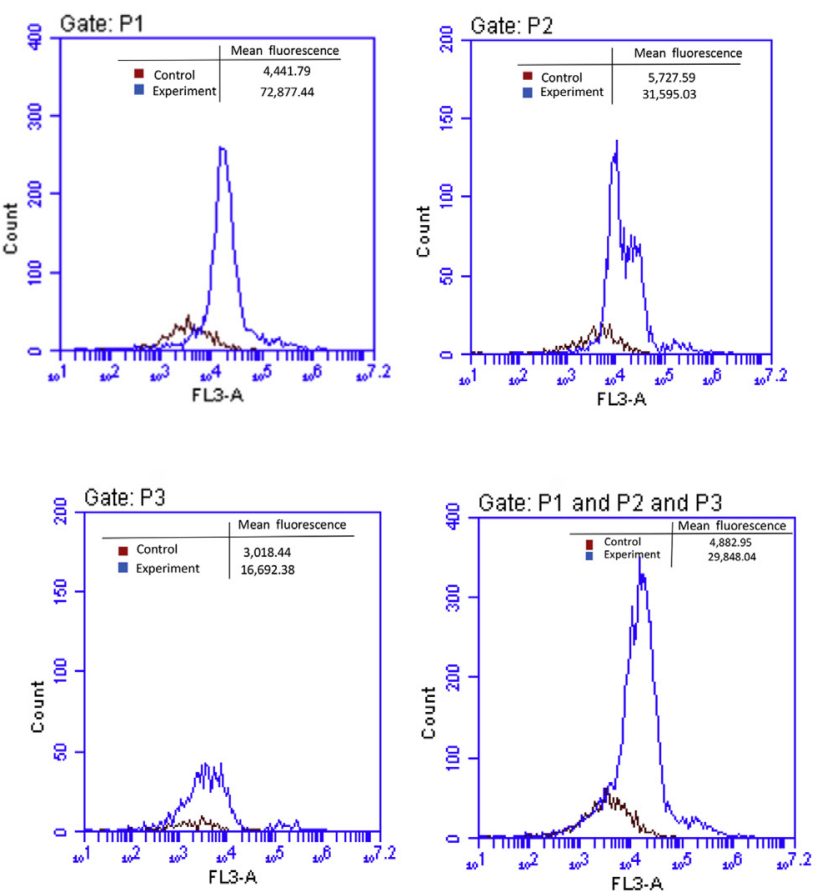
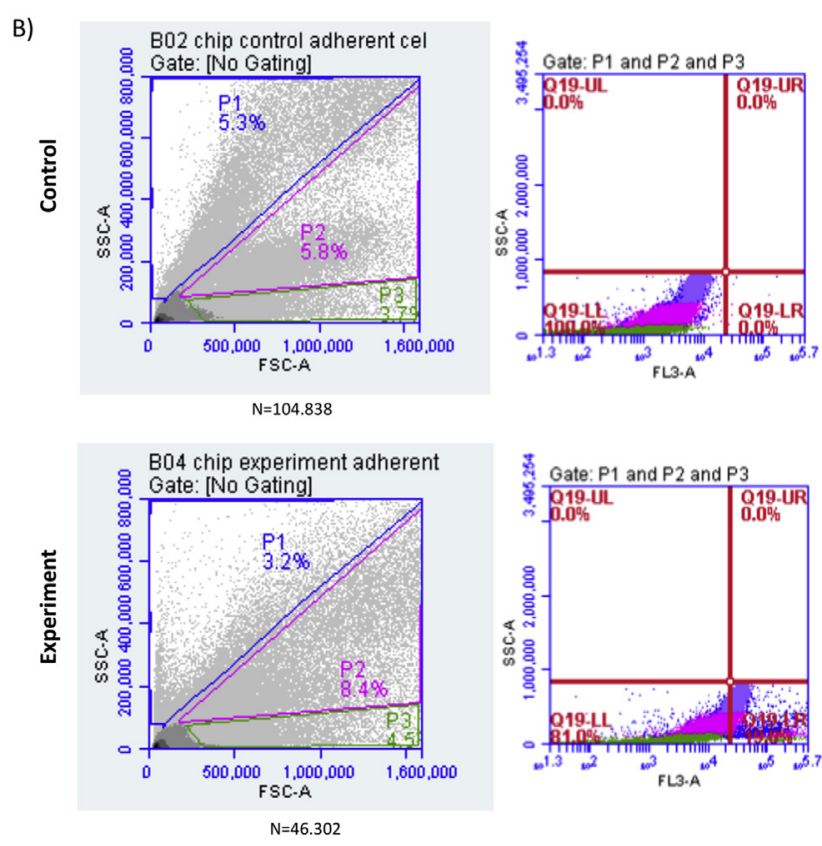

D)

Adherent cells
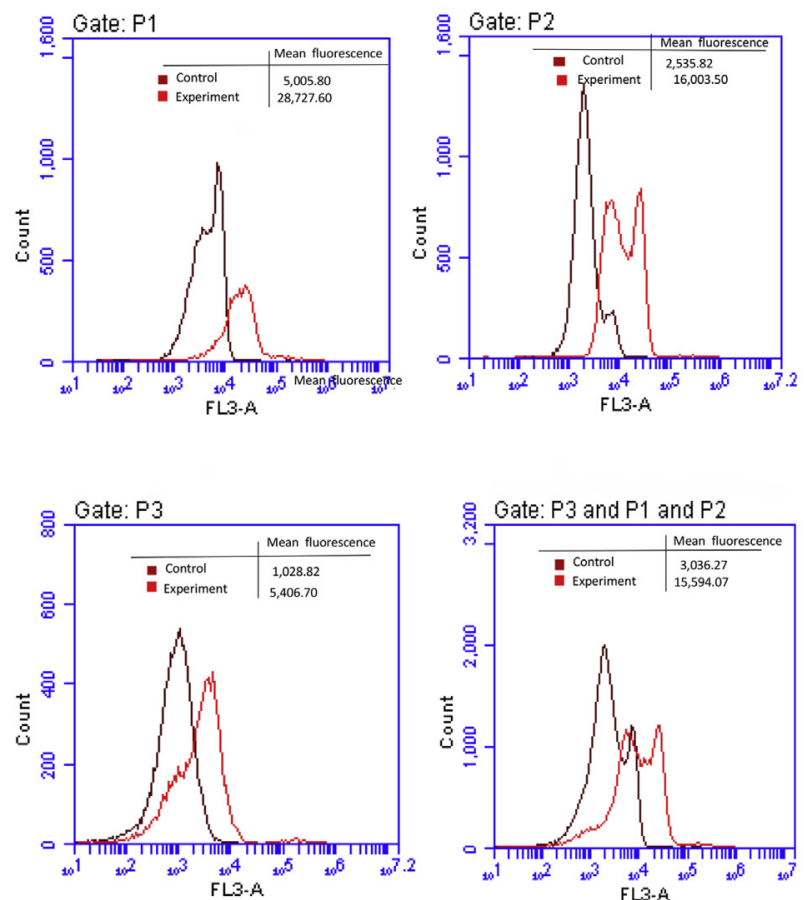

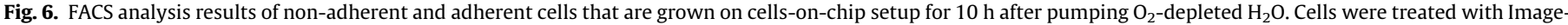

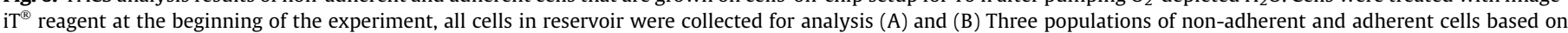

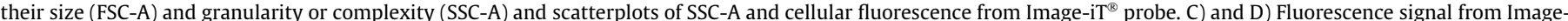
$\mathrm{iT}^{\circledR}$ probe in non-adherent and adherent cells contained in each gate (P1-P3).

experiment. Under the Experiment conditions, 2.3-fold fewer cells $(46,302$ vs 104,838$)$ remained adherent than those in the control conditions. When comparing the scatter plots, it is evident that cells in population P1 decrease whereas the cell proportion in the $\mathrm{P} 2$ population increases in the experiment conditions. Because the population shift occurs on the FSC axis, this suggests increased cell size or swelling upon exposure to the chemical oxygen sinkgenerated microenvironmental hypoxia. Cell swelling is a well- 


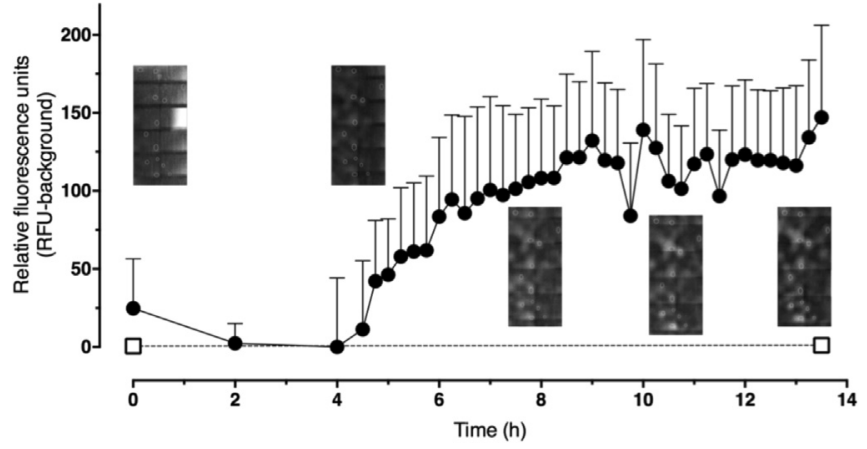

Fig. 7. GFP fluorescence intensity over time in cells on the pool area during pumping of $\mathrm{O}_{2}$-depleted $\mathrm{H}_{2} \mathrm{O}$. GFP fluorescence intensities from the control area at the beginning and end of the experiment are shown for reference (open squares). Cells were transiently transfected with a hypoxia response element (HRE)-GFP expression reporter plasmid. Time-lapse fluorescence from expressed GFP protein was recorded from the pool and control areas.

documented cellular response to hypoxia [20]. Control cells demonstrated low or absent fluorescence in all populations, whereas a significant population (19.6\%) of adherent cells from the experiment conditions demonstrated increased fluorescence signal deriving from the Image-i $\mathrm{T}^{\circledR}$ probe, suggesting exposure to hypoxia. Fig. 6D further demonstrates a population-wide response in the fluorescent signal, demonstrating that hypoxia exposure occurs independent of cell size or granularity. The experiments thus not only confirm microenvironmental exposure but also generation of intracellular hypoxia by the chemical oxygen sink microfluidic method in cells grown on the microfluidic channel architectures.

A HRE-GFP-reporter plasmid transient transfection was used to determine if the observed intracellular hypoxia is translated into intracellular hypoxia signalling and activation of the hypoxia response elements primarily via increased expression and activity of HRE-activating factors (such as HIF-1 $\alpha$ ). Time-lapse fluorescent images were collected from cells grown on the microfluidic channel pool architecture and oxygen-depleted $\mathrm{H}_{2} \mathrm{O}$ was pumped into the channel for $12 \mathrm{~h}$.

Fig. 7 shows GFP fluorescence intensity over time in HIF-1 $\alpha$-GFP vector-transfected cells on the pool and control area. Based on the increased GFP signal, cells in the pool area demonstrated a robust HRE response to microenvironmental $\mathrm{O}_{2}$ depletion by oxygen-free water pumping in the microfluidic channel. Similar to the intracellular signal observed from the fluorescent hypoxia probe, the GFP signal was also sustained over time until the end of the experiment. The relative fluorescence intensity values from similarly transfected cells growing on the control area remained very low throughout the experiment. The fluorescence values for the control area were at the beginning of the recording $0.6 \pm 0.5$ and at the end of the experiment $1.2 \pm 1.4$.

In order to evaluate the lateral oxygen depletion diffusion from the pool area borders, we performed image analysis of oxygen level images taken during oxygen-free water pumping. An average oxygen depletion lateral diffusion of $1.2 \mathrm{~mm}$ with a maximum of $1.8 \mathrm{~mm}$ and a minimum of $0.6 \mathrm{~mm}$ was measured to occur outwards from the pool area border (Supplementary Fig. 3A). For reference we also evaluated the oxygen levels in the control area during pumping of oxygen-free water. The control area demonstrated unchanged and undepleted oxygen concentrations (Supplementary Fig. 3B).

In order to evaluate the lateral oxygen depletion diffusion from the pool area borders, we performed image analysis of oxygen level images taken during oxygen-free water pumping. An average oxygen depletion lateral diffusion of $1.2 \mathrm{~mm}$ with a maximum of
A

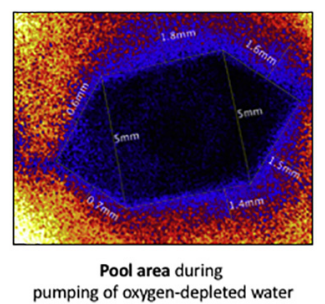

B

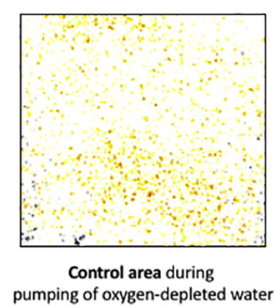

Supplementary Fig. 3. (A) Oxygen imaging of the pool area during oxygendepleted water pumping. The image demonstrates the pool area and measurements of various oxygen diffusion distances from the pool area borders. B) Oxygen imaging of the control area during pumping of oxygen-depleted water in the microfluidic channels demonstrating high oxygen concentration at the control area.

$1.8 \mathrm{~mm}$ and a minimum of $0.6 \mathrm{~mm}$ was measured to occur outwards from the pool area border (Supplementary Fig. 3A). For reference we also evaluated the oxygen levels in the control area during pumping of oxygen-free water. The control area demonstrated unchanged and undepleted oxygen concentrations (Supplementary Fig. 3B).

\section{Discussion}

We demonstrate that the effect of in-liquid chemical oxygen depletion reaction can be localised and physically isolated and contained to affect cells isolated from the microfluidic channel by a PDMS gas-permeable membrane. We utilised sodium sulfite/cobalt nitrate reaction as the oxygen-depleting chemical reaction. We also show that intracellular hypoxia signalling is initiated in human cells cultured on such a microfluidic channel.

The chemical reaction of sodium sulfite/cobalt nitrate was used by Skolimowski et al. [21], to modify bacterial growth conditions on the microfluidic channels. They isolated the culture area from the outside environment in a manner unsuitable for mammalian cell cultures $\left(\mathrm{CO}_{2}\right.$-controlled medium $\mathrm{pH},+37^{\circ} \mathrm{C}$ and regular maintenance of moisture in a standard cell culture incubator). In contrast, we show here that an open atmosphere and exposure to atmospheric concentrations of $\mathrm{O}_{2}$ can be tolerated by the inliquid chemical reaction and its propensity to deplete microenvironmental oxygen. Our results suggest that the range of oxygen depletion through the PDMS is $1.5 \mathrm{~mm}$. Moreover, the oxygen concentration affecting the cells can be controlled by modifying this range as the thickness of the PDMS layer separating the cells from the microfluidic channel/in-liquid oxygen depletion reaction. Peng et al. [22], previously reported a cell culture array with different oxygen tensions. In their experiments, microfluidic application of different concentrations of pyrogallol and $\mathrm{NaOH}$ were used to generate the various hypoxic conditions in which cells were then cultured. Our approach utilised a single liquid pumping with hypoxia/ re-oxygenation of the cell culture generated through control over pumping speed and in-liquid reaction kinetics. Exposure to different levels of $\mathrm{O}_{2}$ can be controlled by the thickness of the PDMS membrane. Cell cultures were maintained with routine fresh medium changes and culture passaging at 2-day intervals. Experiments on microfluidic chips were conducted so that cells in fresh medium were first pipetted into the culture well of the chip, let to adhere and grow for $48 \mathrm{~h}$ after which medium was changed and the experiment (pumping of liquids in the microfluidic channel of the chip) was started. Cell culture on the PDMS membrane in our setup is similar to regular culture conditions under normoxia, when sodium sulfite solution is not used in the microfluidic channel. Our chip architecture permits culturing of cells under normoxia 
immediately next to those exposed to hypoxia. Moreover, because the same culture well and culture medium encompasses both in normoxia and hypoxia, the cell responses are directly and reliably comparable. Moreover, the cells not exposed to hypoxia but in vicinity of the hypoxia-exposed cells present a biologically relevant culture model for investigation of the hypoxia bystander cells [23].

The pool area architecture in our chip allows for even larger culture areas to be exposed to hypoxia. Further upscaling of this setup can produce hypoxic culture plates or dishes. Hypoxic cell culture conditions have been shown to prolong maintenance, stimulate proliferation and regenerative potential of stem cells [24], primary mesenchymal and hematopoietic human cells isolated from the bone marrow $[25,26]$. Because modification of oxygen levels in cell culture have fundamental effects on cell behaviour, several approaches have been utilised to lower oxygen either directly in the medium or in the environment. Moreover, hypoxiamimicking agents such as cobalt chloride [27], or even putative hypoxia induction by 3-nitropropionic acid (a neurotoxin/ mitochondrial succinate dehydrogenase inhibitor) [28], are widely preferred, as true modification of microenvironmental $\mathrm{O}_{2}$-concentrations levels are notoriously laborious to achieve.

Oxygen depletion instigated by the sodium sulfite reaction contained in the microfluidic channel ranged to the microenvironment of cells cultured physically separated from that channel on top of a PDMS membrane. We thus speculated that if in contact with a tissue, a similar sodium sulphite liquid-containing microfluidic channel system, as described here, could also be utilised in vivo to generate a hypoxic tissue layer when in contact with the PDMS membrane for the purpose of stimulating tissue responses by lowering localised microenvironmental oxygen concentrations. Such implants have been suggested to have enhanced therapeutic activities [29]. For example, it has been shown that the regenerative capacity of cardiac stem or progenitor cells can be maintained by hypoxia or lowered oxygen concentrations [30]. This interesting observation is currently under further evaluation in our laboratory.

We first showed that the cobalt-catalysed sodium sulfite oxidation is sufficient to generate an oxygen-depleted environment, and that this environment ranges outside the liquid surface. Because sodium sulfite is consumed in the reaction, reagents must be constantly renewal to deliver sustained oxygen depletion at a given spatial locus. We also showed that a microvolume droplet is sufficient to deliver significant oxygen depletion. Thus, we designed a microfluidic chip to demonstrate the effect of the in-liquid chemical oxygen depletion reaction emplacement. The chip contains three areas; two for oxygen depletion delivery (containing the microfluidic channels) and one control area (without microfluidic channel). Cells growing on this control area are exposed only to any oxygen concentration modifications that expand from the other areas. In our experiments, we showed that this control area, within the same overall culture environment and culture well, remains intact and unaffected by the microenvironmental oxygen modification. This modification, in turn, is delivered to cells in those areas containing the microfluidic channels. This result clearly demonstrates that the effect of our in-liquid chemical oxygen depletion reaction and its microfluidic emplacement under cells cultured in regular cell culture medium and normal cell culture atmosphere is specifically spatially contained and restricted.

\section{Conclusions}

In conclusion, we have shown a novel utilisation of chemical inliquid oxygen sink in a microfluidic channel chip for the generation of cellular microenvironmental hypoxia. Cellular hypoxia and intracellular hypoxia signalling were initiated with the chip construct under normal cell culture conditions. Moreover, with the current architecture and culture conditions, the effects of targeted hypoxia induction in a given cell population on the non-exposed adjacent bystander cells in same culture environment can be studied. Furthermore, we show that by regulating the flowrate, hypoxia-re-oxygenation cycles can be generated in the setup. The current microfluidic chip is expected to open new research possibilities particularly in cancer research and in cardiovascular and neuronal research fields, where cellular microenvironmental hypoxia modelling, bystander cell effects or hypoxic tumour normoxic stroma-interactions [6], and intermittent hypoxia [7], critically influence disease progression and pathology [31,32], and modify regenerative responses [30]. Prior to our technology, it was practically impossible to study these effects in a cell culture model system where only targeted oxygen depletion is introduced to a specific cellular microenvironment while other culture sites and parameters (including culture medium dissolved oxygen) remain unchanged.

\section{Conflicts of interest}

The authors declare no conflicts of interest.

\section{Acknowledgements}

We gratefully acknowledge and thank Ms Lahja Eurajoki for her expert technical assistance, and Ms Noora Aarnio (Biomedicum Flow Cytometry Unit, University of Helsinki) and PhD Antti Siltanen for their expert help with FACS analysis. We thank Sole Lätti MSc for making the graphical illustrations for this article. Mikko Liljeström MSc(Tech.) and Antti Isomäki PhD from the Biomedicum Imaging Unit, University of Helsinki are gratefully acknowledged for their expert technical help on live cell imaging and timelapse microscopy. The HRE-GFP expression reporter plasmid was a kind gift from professor Gregg L Semenza (Johns Hopkins School of Medicine, Baltimore, MD).

\section{References}

[1] M.Y. Koh, G. Powis, Passing the baton: the HIF switch, Trends Biochem. Sci. 37 (2012) 364-372.

[2] Z. Ivanovic, Hypoxia or in situ normoxia: the stem cell paradigm, J. Cell. Physiol. 219 (2009) 271-275.

[3] L.M. Buja, R.S. Vander Heide, Pathobiology of ischemic heart disease: past, present and future, Cardiovasc. Pathol. 25 (2016) 214-220.

[4] J.S. Silvestre, D.M. Smadja, B.I. Lévy, Postischemic revascularization: from cellular and molecular mechanisms to clinical applications, Physiol. Rev. 93 (2013) 1743-1802.

[5] H.K. Elzschig, T. Eckle, Ischemia and reperfusion-from mechanism to translation, Nat. Med. 17 (2011) 1391-1401.

[6] E.L. LaGory, A.J. Giaccia, The ever-expanding role of HIF in tumor and stromal biology, Nat. Cell Biol. 18 (2016) 356-365.

[7] C. Michiels, C. Tellier, O. Feron, Cycling hypoxia: a key feature of the tumor microenvironment, Biochim. Biophys. Acta 2016 (1866) 76-86.

[8] S.C. Oppegard, A.J. Blake, J.C. Williams, D.T. Eddington, Precise control over the oxygen conditions within the Boyden chamber using a microfabricated insert, Lab Chip 10 (2010) 2366-2373.

[9] A. Takano, M. Tanaka, N. Futai, On-chip multi-gas incubation for microfluidic cell cultures under hypoxia, Biomicrofluidics 8 (2014) 061101, https://doi.org/ 10.1063/1.4902941.

[10] H.J. Chiang, S.L. Yeh, C.C. Peng, W.H. Liao, Y.C. Tung, Polydimethylsiloxanepolycarbonate microfluidic devices for cell migration studies under perpendicular chemical and oxygen gradients, J. Vis. Exp. 120 (2017), https://doi.org/10.3791/55292.

[11] E.C. Fuller, R.H. Crist, The rate of oxidation of sulfite ions by oxygen, J. Am. Chem. Soc. 63 (1941) 1644-1650.

[12] A.A. Shaikh, S.M. Javaid Zaidi, Kinetics of catalytic oxidation of aqueous sodium sulfite, React. Kinet. Mech. Catal. 64 (1998) 343-349.

[13] P.M. Wilkinson, B. Doldersum, P.H.M.R. Cramers, L.V. Dierendonck, The kinetics of uncatalyzed sodium sulfite oxidation, Chem. Eng. Sci. 48 (1993) 933-941.

[14] Linek Tvrdik, A generalization of kinetic data of sulphite oxidation systems, Biotechnol. Bioeng. 13 (1971) 353-369.

[15] C.J. Ochs, J. Kasuya, A. Pavesi, R.D. Kamm, Oxygen levels in thermoplastic microfluidic devices during cell culture, Lab Chip 14 (2014) 459-462. 
[16] P.E. Oomen, M.D. Skolimowski, E. Verpoorte, Implementing oxygen control in chip-based cell and tissue culture systems, Lab Chip 16 (2016) 3394-3414.

[17] S. Zhang, M. Hosaka, T. Yoshihara, K. Negishi, Y. Iida, S. Tobita, T. Takeuchi, Phosphorescent light-emitting iridium complexes serve as a hypoxia-sensing probe for tumor imaging in living animals, Cancer Res. 70 (2010) 4490-4498.

[18] J. Schindelin, I. Arganda-Carreras, E. Frise, V. Kaynig, M. Longair, T. Pietzsch, S. Preibisch, C. Rueden, S. Saalfeld, B. Schmid, J.Y. Tinevez, D.J. White, V. Hartenstein, K. Eliceiri, P. Tomancak, A. Cardona, Fiji: an open-source platform for biological-image analysis, Nat. Methods 9 (2012) 676-682.

[19] J. Schindelin, C.T. Rueden, M.C. Hiner, K.W. Eliceiri, The ImageJ ecosystem: an open platform for biomedical image analysis, Mol. Reprod. Dev. 82 (2015) 518-529.

[20] C. Michiels, Physiological and pathological responses to hypoxia, Am. J. Pathol. 164 (2004) 1875-1882.

[21] M. Skolimowski, M.W. Nielsen, J. Emnéus, S. Molin, R. Taboryski, C. Sternberg, M. Dufva, O. Geschke, Microfluidic dissolved oxygen gradient generator biochip as a useful tool in bacterial biofilm studies, Lab Chip 10 (2010) 2162-2169.

[22] C.C. Peng, W.H. Liao, Y.H. Chen, C.Y. Wu, Y.C. Tung, A microfluidic cell culture array with various oxygen tensions, Lab Chip 13 (2013) 3239-3245.

[23] C.L. Sun, E. Kim, C.M. Crowder, Delayed innocent bystander cell death following hypoxia in Caenorhabditis elegans, Cell Death Differ. 21 (2014) 557-567.

[24] A. Mohyeldin, T. Garzón-Muvdi, A. Quiñones-Hinojosa, Oxygen in stem cell biology: a critical component of the stem cell niche, Cell Stem Cell 7 (2010) 150-161.
[25] R. Das, H. Jahr, G.J. Van Osch, E. Farrell, The role of hypoxia in bone marrowderived mesenchymal stem cells: considerations for regenerative medicine approaches, Tissue Eng. Part B: Rev. 16 (2010) 159-168.

[26] M.G. Cipolleschi, P. Dello Sbarba, M. Olivotto, The role of hypoxia in the maintenance of hematopoietic stem cells, Blood 82 (1993) 2031-2037.

[27] Y. Yuan, G. Hilliard, T. Ferguson, D.E. Millhorn, Cobalt inhibits the interaction between hypoxia-inducible factor-alpha and von Hippel-Lindau protein by direct binding to hypoxia-inducible factor-alpha, J. Biol. Chem. 278 (2003) 15911-15916.

[28] C. Münch, B.G. Zhu, A. Leven, S. Stamm, H. Einkörn, B. Schwalenstöcker, A.C. Ludolph, M.W. Riepe, T. Meyer, Differential regulation of $5^{\prime}$ splice variants of the glutamate transporter EAAT2 in an in vivo model of chemical hypoxia induced by 3-nitropropionic acid, J. Neurosci. Res. 71 (2003) 819-825.

[29] J. Zhou, L. Zhao, Hypoxia-mimicking Co doped $\mathrm{TiO}_{2}$ microporous coating on titanium with enhanced angiogenic and osteogenic activities, Acta Biomater. 43 (2016) 358-368.

[30] Y. Nakada, D.C. Canseco, S. Thet, S. Abdisalaam, A. Asaithamby, C.X. Santos, A. M. Shah, H. Zhang, J.E. Faber, M.T. Kinter, L.I. Szweda, C. Xing, Z. Hu, R.J. Deberardinis, G. Schiattarella, J.A. Hill, O Oz, Z Lu, C.C. Zhang, W. Kimura, H.A Sadek, Hypoxia induces heart regeneration in adult mice, Nature 541 (2017) 222-227.

[31] M. Hornsveld, T.B. Dansen, The hallmarks of cancer from a redox perspective, Antioxid. Redox Signal. 25 (2016) 300-325.

[32] A.L. Harris, Hypoxia-a key regulatory factor in tumor growth, Nat. Rev. Cancer 2 (2002) 38-47. 